\title{
La encefalitis letárgica de von Economo y la pandemia de la gripe española en Bogotá y Medellín: reseña histórica cien años después
}

\author{
Carlos Santiago Uribe' ${ }^{1}$, Adolfo L. González², Paulina González ${ }^{3}$ \\ ${ }_{1}$ Servicio de Neurología, Universidad de Antioquia, Medellín, Colombia \\ 2 Grupo de Historia de la Medicina Antioqueña, Facultad de Medicina, Universidad de Antioquia, \\ Medellín, Colombia \\ ${ }^{3}$ Clínica Universitaria Bolivariana, Medellín, Colombia
}

Recibido: $20 / 08 / 18$

Aceptado: $31 / 01 / 19$

Publicado: 04/02/19

Citación:

Uribe CS, González AL, González P. La encefalitis letárgica de von Economo y la pandemia de la gripe española en Bogotá y Medellín: reseña histórica cien años después. Biomédica. 2019;39: 8-16 https://doi.org/10.7705/biomedica.v39i1.4677

\section{Correspondencia:}

Carlos Santiago Uribe, Departamento de Neurología, Hospital Universitario San Vicente Fundación, Sala de Neurología Clínica, Calle 64 N51 D-154, bloque 6, Medellín, Colombia

Teléfono: (0574) 2192435

curibe35@yahoo.com

\section{Contribución de los autores:}

Carlos Santiago Uribe y Paulina González: búsqueda y revisión bibliográfica, redacción y revisión final Adolfo León González: consulta de fuentes primarias, redacción y revisión final

Financiación:

No se recibió ningún tipo de financiación por el desarrollo de este artículo.

Conflicto de intereses:

Los autores declaran no tener ningún conflicto de intereses.
La encefalitis letárgica de von Economo es un trastorno neuropsiquiátrico de posible origen autoinmunitario, en el cual se afectan los ganglios basales. Esta reacción puede ocurrir luego de una infección aguda por diversos agentes virales o bacterianos. Dado que aparece cuando ya se ha resuelto el cuadro agudo, se ha propuesto el mecanismo del mimetismo molecular para explicar la lesión autoinmunitaria. Se han reportado diversos casos a lo largo del tiempo, pero fue con la pandemia de influenza de 1918, conocida como la gripe española, que la encefalitis letárgica alcanzó niveles de epidemia, con casos reportados hasta 1923 en diversos países.

La pandemia de la gripe española se extendió a Colombia durante los últimos meses de 1918 y afectó varias ciudades, principalmente Bogotá, donde se reportó el mayor número de enfermos y muertos. Con este trabajo se busca rememorar, cien años después, el ingreso de la gripe española a nuestro país y sus principales complicaciones, entre las que se describieron algunos casos de encefalitis letárgica.

Palabras clave: encefalitis; autoinmunidad; ganglios basales; influenza pandémica, 19181919.

Von Economo's encephalitis lethargica and the Spanish flu pandemic in Bogotá and Medellín (Colombia): An historic review one hundred years after

Von Economo's encephalitis is a neuropsychiatric disorder of possible autoimmune origin, which affects basal ganglia. This reaction may occur secondary to infection by different viral or bacterial agents. Given that it appears after the acute episode has disappeared, molecular mimetism has been proposed to explain the autoimmune lesion. Several cases have been reported through time, but it was with the 1918 flu pandemic, known as the Spanish flu, that lethargic encephalitis reached epidemic levels with cases reported until 1923 in various countries.

The Spanish flu pandemic appeared in Colombia at the end of 1918 in several cities but it affected especially Bogotá where the highest number of patients and deaths was reported. Our purpose with the present work was to commemorate the arrival of the Spanish flu to our country after one hundred years, as well as to reflect on its main complications, which included some lethargic encepahilitis cases.

Key words: Encephalitis; autoimmunity; basal ganglia; influenza pandemic, 1918-1919.

La encefalitis letárgica de von Economo es un trastorno neuropsiquiátrico, en el cual probablemente ocurre una reacción autoinmunitaria anormal dirigida contra antígenos de los ganglios de la base. Al igual que otras encefalitis autoinmunitarias mediadas por anticuerpos (1), suele presentarse luego de una infección aguda causada por agentes virales (influenza) o bacterianos (estreptococo) y manifestarse con una gran variedad de síntomas, entre los cuales los más comunes son trastornos del sueño, movimientos anormales (especialmente, parkinsonismo) y alteraciones neuropsiquiátricas (1).

Si bien previamente se habían descrito casos de pacientes con cuadros similares, fue en 1917 cuando Constantin von Economo describió y definió esta condición que lleva su epónimo (2) y que, en el 2017, cumplió 100 años (3). 
En el transcurso de la pandemia de influenza de 1918, conocida como la gripe española, se incrementaron los casos de pacientes con esta encefalitis. A partir de ese momento y durante varios años más (1923-1927), se reportaron decenas de miles de personas afectadas en todo el mundo por diversas formas de encefalitis, hasta el punto de alcanzar niveles de epidemia en Europa y Estados Unidos. En este último país, el pico de la enfermedad se registró en 1923, cuando se reportaron 200 muertes por encefalitis letárgica de von Economo (4). Después de la década de 1920, la incidencia de la enfermedad disminuyó sustancialmente, aunque hoy siguen reportándose casos esporádicamente sin alcanzar nunca las cifras de la epidemia de 1918.

Actualmente, autores como Dale, et al., la consideran una forma de encefalitis autoinmunitaria posinfecciosa (1) probablemente relacionada con la presencia de autoanticuerpos reactivos contra antígenos de los ganglios de la base (1). Por su parte, Dourmashkin, et al. (5), han propuesto otras etiologías, como las infecciones por enterovirus, pero, aunque las hipótesis son varias, la verdadera etiología, según Hoffman, et al., sigue sin conocerse (6). La relación entre la encefalitis letárgica de von Economo y el parkinsonismo posencefalítico es compleja, según Vilensky, et al. (7), y puede haber otras causas diferentes al parkinsonismo.

La pandemia de la gripe española se extendió durante los últimos meses de 1918 en varias ciudades de Colombia, principalmente Bogotá, donde se reportó el mayor número de enfermos y muertes. En el 2018, se conmemoraron los cien años de la pandemia de la gripe española, que llevó a la muerte, aproximadamente, a 40 millones de personas en todo el mundo.

El propósito de esta revisión narrativa fue conmemorar la pandemia de la gripe española en el centenario de su aparición, intentar definir el impacto que tuvo en nuestro país, en especial en Bogotá y Medellín, y comprender el contexto y las condiciones económicas, sociales, higiénicas y de salud del momento, con el fin de conocer y analizar las medidas que se tomaron para tratar a los enfermos y controlar la propagación de la epidemia, así como determinar la presencia o ausencia de casos de encefalitis letárgica.

\section{Von Economo y la descripción de la encefalitis letárgica}

Constantino von Economo (1876-1931), médico rumano, comunicó en 1917 a la Sociedad Vienesa de Psiquiatría y Neurología, su descripción de la encefalitis letárgica. Su comunicación suscitó una gran polémica, pues, por una parte, Jean Renée Cruchet reclamó la autoría con base en las observaciones que había realizado en 1915 en el frente de guerra de Verdún, en tanto que otros argumentaron que lo descrito por von Economo eran las secuelas de las manifestaciones encefálicas de la gripe española (8).

Von Economo describió tres formas clínicas de la que él denominó encefalitis letárgica: 1) una forma somnolienta-oftalmopléjica (epidemia de Viena), que se inicia con un cuadro gripal, pero que posteriormente se caracteriza por somnolencia excesiva y confusión progresiva hasta que el paciente llega a un estado de estupor y entra en coma. En el examen neurológico pueden encontrarse, además, oftalmoplejía externa e interna, crisis oculógiras, nistagmo, discinesias y signos cerebelosos o piramidales; 2) una forma acinética y muda (epidemia de Londres), o de parkinsonismo agudo acompañado a veces por catatonia, estupor y mutismo, y 3) una forma hipercinética (epidemia de Rumania), caracterizada por inquietud permanente, discinesias, manía y alucinaciones visuales, que con frecuencia se confunde con un síndrome catatónico secundario a un trastorno psicótico (esquizofrenia). 
Entre 1918 y 1927, se reportó una gran cantidad de pacientes con manifestaciones encefalíticas asociadas con la pandemia de gripe española.

\section{Encefalitis letárgica después de la gripe española}

Después de la década de 1920, disminuyó sustancialmente el número de pacientes con cuadros encefalíticos, aunque continuaron reportándose de manera esporádica (1).

En años recientes, se han planteado diversas hipótesis fisiopatológicas para explicar la encefalitis letárgica de von Economo.

Reid, et al., revisaron la descripción original de von Economo y escogieron ciertos hallazgos que ayudan a diferenciar esta condición de otras encefalitis con manifestaciones extrapiramidales (9), como las del parkinsonismo agudo, o después de meses o años (crisis oculógiras, excluidas las inducidas por neurolépticos o levodopa; alteraciones del sueño y vigilia; cambios pupilares; otros movimientos involuntarios como ladistonía o las mioclonías; cambios mentales; signos piramidales, y trastornos respiratorios).

Por su parte, Howard, et al., agregaron a estos criterios clínicos las anormalidades en el líquido cefalorraquídeo (aumento de leucocitos, hiperproteinorraquia y presencia de bandas oligoclonales), y la presencia de ondas lentas y alteración en los potenciales evocados en el electroencefalograma (10).

Blunt, et al., describieron dos casos, uno de ellos tratado con $1 \mathrm{~g}$ diario de metilprednisolona intravenosa durante tres días, con lo cual se logró la mejoría. Ambos casos cumplían con los criterios de la enfermedad, aunque el primero correspondía al fenotipo acinético con mutismo y requirió, además, levodopa. Los dos pacientes descritos fueron tratados inicialmente con aciclovir, sin mejoría alguna (11).

En el estudio de Dale, et al., se describen 20 pacientes con cuadros clínicos sugestivos de encefalitis letárgica de von Economo, muy similar a las descripciones históricamente conocidas, con trastornos del sueño, letargia, signos de parkinsonismo, discinesias y alteraciones neuropsiquiátricas (1). En este trabajo, los autores mencionan que, si bien previamente se consideraba que la pandemia del virus de la influenza de 1918 era la responsable de la encefalitis letárgica de von Economo, no ha sido posible corroborar esta hipótesis.

En algunos estudios de detección del virus de la influenza mediante reacción en cadena de la polimerasa (PCR) en tejidos provenientes de pacientes fallecidos durante la epidemia de gripe española, no se evidenció la presencia del virus en el encéfalo ni en las vías respiratorias. Sin embargo, se detectaron bandas oligoclonales y anticuerpos contra los ganglios basales en un gran porcentaje de pacientes $(8,11,12)$.

También es interesante anotar que se documentó la presencia de anticuerpos contra el estreptococo beta-hemolítico en $65 \%$ de los pacientes, lo cual sugiere un mecanismo de mimetismo molecular que termina generando un daño mediado por el sistema inmunitario activado contra los ganglios de la base, como ocurre en la corea de Sydenham y en el grupo de trastornos neuropsiquiátricos autoinmunitarios asociados con infecciones por estreptococo, denominado PANDAS (Pediatric Autoimmune Neuropsichiatry Association with Streptococus) (8). 
La respuesta de algunos pacientes -como los descritos por Blunt, et al.-a las altas dosis de esteroides, apoyaría la teoría del origen autoinmunitario de esta encefalitis (11). En 1987, Howard, et al., presentaron cuatro pacientes con una encefalitis idéntica a la descrita por von Economo, pero cuyos potenciales evocados en el electroencefalograma y sus autopsias evidenciaban un compromiso cortical mucho más extenso que el descrito previamente (10).

Las pruebas serológicas y los cultivos virales practicados en estos pacientes, no revelaron el agente infeccioso, pero la presencia de bandas oligoclonales IgG en el líquido cefalorraquídeo de tres de ellos durante la fase aguda de la enfermedad, hacen pensar en una etiología viral. Y, aunque no ha sido posible confirmar esta teoría, dado que no se ha hallado virus ni en el encéfalo ni en las vías respiratorias, otros autores señalan las limitaciones técnicas de las pruebas en muestras provenientes de cadáveres, ya que se reduce su sensibilidad. Además, se requeriría un estudio mucho más exhaustivo para excluir los diferentes tipos de virus de influenza y de otros, como los enterovirus, el virus de Coxsackie, el de la encefalitis japonesa, el de la fiebre del oeste del Nilo, el de San Luis y el HIV (4).

Hoy puede afirmarse que no hay evidencia que sustente el origen viral de la enfermedad. De todas maneras, resulta interesante que esta encefalitis corresponda a una reacción posinfecciosa mediada por la reacción autoinmunitaria, al igual que sucede en PANDAS y en otras encefalitis autoinmunitarias.

En cuanto a las secuelas y el pronóstico de esta enfermedad, Duncan describió los déficits neurológicos persistentes, los cuales incluían compromiso de las funciones mentales, parkinsonismo, parálisis de los nervios craneales III, IV, VI y VII, así como trastornos motores como hemiparesia, monoparesia y monoplejía (13).

Oliver Sacks, neurólogo fallecido en el 2015, describió en su libro "Despertares" las historias de 20 de sus pacientes, sobrevivientes de la gran epidemia de encefalitis letárgica de von Economo con parkinsonismo posencefalítico, y del asombroso 'despertar' que experimentaron cuarenta años más tarde cuando les administró un medicamento de reciente aparición en el mercado: la levodopa.

"[...] entré en contacto con los notables pacientes postencefalíticos que estaban ingresados desde la gran epidemia de enfermedad del sueño, o encefalitis letárgica, que se desencadenó justo después de la Primera Guerra Mundial. Von Economo, que había descrito la encefalitis letárgica medio siglo antes, calificó a los pacientes más gravemente afectados por ella de "volcanes extinguidos". En la primavera de 1969, de un modo que von Economo no habría podido imaginar, de un modo que, de hecho, nadie habría podido imaginar o predecir, aquellos "volcanes extinguidos" volvieron a la vida [...]" (14).

En Colombia hubo casos de esta encefalitis, como lo demuestra el informe de Roberto Franco en el Repertorio de Medicina y Cirugía, del cual se hablará más adelante. Como dato anecdótico, aunque de evidencia dudosa (8), Lieberman atribuye el parkinsonismo de Hitler y sus trastornos psiquiátricos al hecho de haber sufrido en su juventud la encefalitis de von Economo (15).

\section{Gripe española en Colombia}

La pandemia afectó varias ciudades del país en los últimos meses de 1918, principalmente en octubre y noviembre. Aunque algunos autores han 
considerado que la primera y principal ciudad afectada fue Bogotá, hay registros en los que aparecen casos fatales a partir de septiembre en Cartagena:

"[...] La Gaceta Médica en Cartagena registró 23 muertes por gripa, 21 en noviembre, 1 en diciembre y 1 en septiembre. Este último sería el primer caso reportado en las fuentes primarias consultadas, lo que indica que fue la Costa Caribe el lugar de ingreso de la pandemia de 1918 y no Bogotá, como hasta ahora se ha afirmado [...]" (16).

Si bien se ha debatido sobre cuál fue el punto de ingreso de la pandemia al país, no hay duda de que la capital fue la más afectada en términos de morbilidad y mortalidad. En 1918, Bogotá contaba con 141.639 habitantes, la mayoría de ellos sometidos a condiciones económicas e higiénicas precarias. Se estima que entre el 60 y el $80 \%$ de la población enfermó de gripa (alrededor de 100.000 habitantes) (16) y que hubo cerca de 1.500 personas fallecidas:

"[...] Datos oficiales señalan que del 1 al 20 de octubre se presentaron 250 muertes, y durante los días 21 al 31 de octubre, 1.150 más, todas ellas atribuibles a la epidemia de gripa, siendo estas fechas las de mayor tasa de mortalidad reportada [...]" (17).

Se postula que la altitud -Cundinamarca y Boyacá se encuentran ubicadas entre los 2.600 y los 3.000 metros sobre el nivel del mar-y las condiciones climáticas (temperatura media de $14{ }^{\circ} \mathrm{C}$ en Bogotá), favorecieron la mayor incidencia de la enfermedad y de complicaciones.

\section{Prevención y tratamiento}

La Junta Central de Higiene, máxima autoridad de higiene pública en Colombia en aquel entonces, presentó las siguientes apreciaciones el 23 de octubre de 1918:

"[...] Tratándose de una enfermedad que se propaga con gran rapidez, favorecida por las condiciones climatéricas especiales y todavía no bien determinadas, la higiene no dispone, como en otras epidemias, de medios eficaces para detener su propagación y, por consiguiente, no se puede confiar en medidas administrativas para dominar la epidemia y solamente pueden aconsejarse prescripciones individuales, no para detener la epidemia sino para disminuir su gravedad y prevenir las complicaciones. Estas medidas aconsejadas por la ciencia, son:

1) Aislar, en cuanto fuere posible, los ancianos, niños y personas que sufren de enfermedades del aparato respiratorio, por ser más susceptibles al contagio.

2) Debe procurarse no estar cerca de un enfermo de gripa, pues las mucosidades de la nariz y de los bronquios que se desprenden de la tos y el estornudo llevan al contagio.

3) Los esputos y demás secreciones mucosas del enfermo deben recibirse en una vasija que contenga un líquido desinfectante, como una solución de formol al cinco por ciento, o carbonato de soda en la misma proporción. 4) Los enfermos de gripa deben estar abrigados y evitar los cambios de temperatura.

5) Todo enfermo de gripa, tanto para destruir el germen de su propio organismo y para impedir la contaminación, debe lavarse la boca y las fosas nasales con una solución antiséptica tibia, tales como solución boricada al cinco por ciento, agua oxigenada muy diluida, una parte de agua oxigenada por dos de agua hervida, $u$ ocho gotas de tintura de yodo en un vaso de agua hervida,

6) Tanto para tratar la enfermedad como para prevenirla, está aconsejado el sulfato de quinina en dosis pequeñas, de veinte a treinta centigramos por la mañana y por la tarde, 
7) Está igualmente indicado hacer uso de bebidas calientes, como infusiones de té, de tilo, etc. con una cucharada de Espíritu de Minderero [...]" (18).

En lo referente a la prevención y el tratamiento de la gripa, llama la atención la recomendación médica de los enjuagues, por su gran capacidad germicida frente al agente de la enfermedad. Es por eso que los médicos en Medellín recomendaron utilizar como desinfectante de la nariz y la garganta, la siguiente fórmula magistral, como lo consigna el diario El Espectador en su edicición del 9 de noviembre de 1918:

"[...] Mentol 2 gramos, Eucaliptol 10 gramos, Alcohol: 100 gramos. Rotular para inhalaciones. Todo individuo puede mantener en el bolsillo un frasquito de boca ancha con un poco de esta preparación para aspirarla frecuentemente; también puede usarla en el pañuelo [...]".

En cuanto al empleo de sulfato de quinina, este aparece a finales del siglo XIX y en las primeras décadas del XX como una verdadera panacea para el tratamiento de muchas enfermedades: se utilizaba como analgésico, contra las fiebres, el paludismo, las caquexias de variada etiología y como tonificante, entre otros usos (19).

\section{Complicaciones graves de la gripa y la encefalitis letárgica de von Economo en Bogotá}

El 7 diciembre de 1918, el médico Marcelino Arango, quien era el presidente de la Junta Nacional Organizadora de la Lucha Antituberculosa, informaba que:

"[...] Acaba de pasar la terrible epidemia de gripa que había causado numerosas víctimas, no sólo en esta Capital, sino en varias ciudades y poblaciones del país. Su acción devastadora se ha extendido a todas las capas sociales, sin respetar a las personas que gozaban de comodidades, ni a las que carecían de ellas. Todos por igual hemos sufrido su influencia y por lo mismo a todos nos incumbe trabajar porque (sic) no se repita y por atenuar sus funestas consecuencias. Sabido es que las complicaciones más graves de la gripa se presentan en el aparato respiratorio, y en la epidemia que pasó se pudo comprobar que las defunciones fueron producidas casi en su totalidad, por neumonías y bronconeumonías. Y si a esto se agrega que la enfermedad produce una acción depresiva sobre el sistema nervioso, es de suponer que muchos de los enfermos que escaparon de la muerte, han quedado notablemente debilitados y en condiciones propicias para adquirir varias enfermedades y, especialmente, la tuberculosis [...]" (20).

Si bien esta mención de efectos depresivos sobre el sistema nervioso es inespecífica, no puede despreciarse, sobre todo teniendo en cuenta las variantes fenotípicas de la enfermedad mencionadas previamente, las cuales incluyen somnolencia y parkinsonismo e, incluso, síndromes catatónicos que podrían considerarse como síntomas o efectos "depresivos" o "debilitantes".

Roberto Franco reportó pacientes con encefalitis letárgica de von Economo (21) con amplia referencia a los diferentes cuadros clínicos. Uno de estos pacientes presentó la forma mesencefálica con compromiso del sueño (narcolepsia), del hipotálamo y de la hidratación (diaforesis, poliuria), así como disartria, disfagia y trastornos psíquicos, descripción que recuerda la forma somnolienta-oftalmopléjica descrita por von Economo.

Llama la atención que, en su artículo "Encefalitis Letárgica en Bogotá", aparecido en 1943 en la Revista de Medicina y Cirugía, J. Hernando Ordóñez 
describe que se han presentado varios casos de esta encefalitis desde 1923: el primero, descrito por Roberto Franco, ya fue mencionado, y otros 15 casos más objeto de las observaciones clínicas del doctor Ordoñez, la mayoría de la forma somnolienta-oftalmopléjica de von Economo, de los cuales cinco pacientes murieron, es decir, el 33,3\%. No se describieron secuelas. Hasta donde se sabe, en Medellín no se reportaron casos de encefalitis letárgica de von Economo (22).

\section{Epidemia de la gripa en Medellín}

En Medellín, con condiciones de altitud y clima diferentes a las de Bogotá (una altitud de 1.538 metros sobre el nivel del mar y una temperatura media de $22{ }^{\circ} \mathrm{C}$, con variaciones extremas de 8 grados hacia arriba y hacia abajo), no hay estaciones propiamente dichas, al igual que en toda la zona tórrida, y se alternan épocas de lluvia y de sequedad cada tres meses. En 1918, la ciudad contaba con 79.146 habitantes, 51.951 de los cuales vivían en la cabecera del municipio y 27.195 en sus seis fracciones (23).

En octubre de 1918, la Comisión Sanitaria del Municipio de Medellín, máxima autoridad sanitaria de la ciudad, al informarse de los terribles estragos producidos por la epidemia de gripa en la capital de la República y conociendo la imposibilidad de evitar su entrada a la ciudad, comenzó a tomar medidas preventivas en conjunto con la Dirección Departamental de Higiene y de la Gobernación del Departamento de Antioquia, con el fin de prevenir en cuanto fuere posible la repetición de las escenas de abandono, sufrimiento y muerte que tan frecuentemente se estaban dando en Bogotá.

A fines de ese mes, comenzaron a presentarse los primeros casos aislados de gripa en Medellín, por lo cual se dividió el casco de la ciudad en seis zonas con el ánimo de controlar la epidemia, entre ellas, El Poblado, La América, Belén y San Cristóbal. Para asistir a los enfermos hospitalizados, se solicitó el concurso de las Hermanas de la Caridad de la Presentación. Una de las primeras acciones de la Gobernación de Antioquia fue clausurar de manera inmediata los establecimientos de educación; también, consiguió que la Dirección de Instrucción Pública cediera el edificio de la Escuela Modelo (ubicada en la actual carrera Bolívar con calle La Paz) para abrir un 'hospital de gripa', el cual fue dotado en menos de 24 horas con todos los elementos necesarios para la atención de los enfermos. Este hospital se puso al servicio con 130 camas y su sala de hombres fue dirigida y atendida por el médico bacteriólogo Gabriel Toro Villa.

Sin embargo, el Hospital de la Escuela Modelo pronto se quedó corto ante el avance de la epidemia: durante los diez primeros días de noviembre de 1918, se incrementó de tal manera el número de enfermos, que fue necesario fundar otros dos hospitales, uno en la desocupada Plaza de Flórez y otro localizado en la calle de Pichincha. Se nombraron, entonces, nuevos médicos, enfermeros, vigilantes y agentes de policía, aunque se reportaron varias irregularidades en la atención en estos hospitales debidas al contagio de varios médicos y enfermeras con la enfermedad. Además, se contrató el despacho permanente de fórmulas con las boticas de Peña, Moderna, Fernández Quevedo, Junín, San José y Escobar.

A todos los médicos y practicantes que trabajaron en los tres hospitales, se les exigieron registros con los nombres de los enfermos asistidos en los que debían señalarse las complicaciones y defunciones. Cuando la epidemia estaba terminando, se trasladaron 39 enfermos de los tres hospitales de griposos al Hospital de San Juan de Dios de Medellín. 
Para los primeros días de diciembre, la epidemia estaba controlada en esta ciudad y, una vez se dio por terminada, los tres edificios que se habían acondicionado como hospitales fueron rigurosamente desinfectados.

En los sesenta días que duró la epidemia en Medellín, se registraron 18.088 enfermos, de los cuales 56 fallecieron. Las complicaciones más frecuentes fueron hemorragia (sobre todo epistaxis, gastrorragias, enterorragias y metrorragias), bronconeumonía, otitis, algunos abortos y muchas enteritis (24).

En el informe del director de la Comisión Sanitaria de Medellín, no se especificó la etiología de las complicaciones de los enfermos fallecidos, pero llama la atención que las más frecuentes fueron de orden hemorrágico. Tampoco se registraron pacientes con "acciones depresivas sobre el sistema nervioso”, como sí sucedió en Bogotá.

\section{Conclusiones}

La encefalitis letárgica de von Economo recibe su nombre de Constantino von Economo, quien hizo la primera descripción y caracterización clínica de la enfermedad en 1917. A partir de entonces, se han seguido describiendo casos de manera esporádica y se ha profundizado en el conocimiento de la etiología y la patología de esta complicación neuropsiquiátrica, que hoy se considera de origen autoinmunitario postinfeccioso. Dicha enfermedad alcanzó niveles de epidemia por su asociación con la gripe española, la cual afectó a miles de personas en diversos países, entre ellos Colombia, donde se reportaron los primeros casos de enfermos y muertos en 1918.

A los 100 años del ingreso de la gripe española al país, puede afirmarse que, según las fuentes investigadas, Bogotá fue la ciudad más afectada, probablemente por sus condiciones climáticas. En la capital se reportaron varias complicaciones graves e, incluso, algunos pacientes con encefalitis letárgica de von Economo, principalmente con la forma somnolientaoftalmopléjica. En Medellín, no se reportaron casos de esta encefalitis.

\section{Referencias}

1. Dale R, Church AJ, Surtees R, Lees A, Adcock JE, Harding B, et al. Encephalitis lethargica syndrome: 20 new cases and evidence of basal ganglia autoimmunity. Brain. 2004;127:21-33. https://doi.org/10.1093/brain/awh008

2. Kay Y, Uysal H, Akkoyunlu G, Sarikcioglu L. Constantin von Economo (1876-1931) and his legacy to neuroscience. Childs Nerv Syst. 2016;32:217-20. https://doi.org//10.1007/s00381015-2647-0

3. Lutters B, Foley P, Kohler P. The centennial lesson of encephalitis lethargica. Neurology. 2018;90:563-7. https://doi.org/10.1212/WNL.0000000000005176

4. Reid AH, McCall S, Henry JM, Taubenberger JK. Experimenting on the past: The enigma of von Economo's encephalitis lethargica. J Neuropathol Exp Neurol. 2001;60:663-70. https:// doi.org/10.1093/jnen/60.7.663

5. Dourmashkin R, Dunn G, Castano V, Sherman McCall. Evidence for an enterovirus as the cause of encephalitis lethargica. BMC Infect Dis. 2012;12:136-56. https://doi. org/10.1186/1471-2334-12-136

6. Hoffman LA, Vilensky JA. Encephalitis lethargica: 100 years after the epidemic. Brain. 2017;140:2246-51. https://doi.org/10.1093/brain/awx177

7. Vilensky JA, Gilman S, McCall S. A historical analysis of the relationship between encephalitis lethargica and postencephalitic Parkinsonism: A complex rather than a direct relationship. Mov Disord. 2010;25:1116-23. https://doi.org//10.1002/mds.22908

8. Salamano R. Encefalitis de Von Economo (encefalitis letárgica o epidémica). Una enfermedad misteriosa. Arch Med Int. 2015;38:1135-44. 
9. Reid D, Scholtz C, Swash M. Post-encephalitic Parkinsonism: Current experience. J Neurol Neurosurg Psychiatry. 1981;44:670-6. https://doi.org/10.1136/jnnp.44.8.670

10. Howard RS, Lees AJ. Encephalitis lethargica. Brain. 1987;110:19-33

11. Blunt SB, Lane RJM, Turyanski N, Perkin GD. Clinical features and management of two cases of encephalitis lethargica. Mov Disord. 1997;12:354-9. https://doi.org/10.1002/ mds. 870120314

12. Holt WL Jr. Epidemic encephalitis: A follow up of 266 cases. Archives of Neurology \& Psychiatry. 1937;38:1135-44.

13. Duncan AG. The sequelae of encephalitis lethargica. Brain. 1924;47:76-95.

14. Sacks O. Despertares. Barcelona: Editorial Anagrama, S.A.; 2005. p. 598.

15. Lieberman A. Adolf Hitler had post-encephalitic Parkinsonism. Parkinsonism Relat Disord. 1996;2:95-103. https://doi.org/10.1016/1353-8020(96)00005-3

16. Manrique F, Martínez A, Meléndez B, Ospina J. La pandemia de gripe de 1918-1919 en Bogotá y Boyacá, 91 años después. Dynamis. 2009;13:287-307.

17. Martínez M, AF, Manrique F, Meléndez B. La pandemia de gripa de 1918 en Bogotá. Dynamis 2007;27:287-307.

18. Lobo-Manuel N. Oficio enviado al Sr. Gobernador de Cundinamarca por el Presidente de la Junta Central de Higiene el Bogotá 23 de octubre de 1918. Antioquia Gaceta Departamental. 1918;1466:10642.

19. Del Baño R. Historia de la tónica II, sulfato de quinina. Fecha de consulta: 26 de febrero de 2018. Disponible en: http://www.elclubdelgintonic.com/la-historia-de-la-tonica-ii/

20. Arango M. Circular Bogotá del 7 de diciembre de 1918. Antioquia Gaceta Departamental. 1919;1516:232.

21. Franco RE. Encefalitis letárgica. Repertorio de Medicina y Cirugía. 1923;15:19-28.

22. Ordóñez JH. Encefalitis letárgica en Bogotá. Presentación de casos clínicos. Repertorio de Medicina y Cirugía. 1943;2:233-57.

23. Departamento Administrativo Nacional de Estadística. Medellín en cifras, ciudad tricentenaria (1675- 1975). Bogota: La Regional; 1976. p. 33-4.

24. Duque JM. Informe correspondiente al mes de diciembre de 1915 enviado al Sr. Presidente del H. Concejo Municipal. Crónica Municipal de Medellín. 1919;242:1923-5. 